\title{
Comparative Analysis of Methods and Tests for Testing Colour Vision of Professional Seafarers
}

\author{
Veljko Rogošić, Lovro Bojić, Nikola Kolja Poljaka, Darko \\ Duplančićb, Pero Vidanc, Blanka Ivančić-Kačer ${ }^{c}$, Rosanda \\ Mulićc
}

There are differences among official standards of testing colour vision among different countries, conditioned by out-ofdate, but still enforceable laws and codes. These standards refer to professions in the maritime, air, rail and road traffic. The criteria for testing colour vision are significantly more severe for professionals involved in traffic. For complex diagnostics of colour vision disorder (dyschromatopsia) there are a number of well-known diagnostic methods and tests (of different cost, validity and year of production) at disposal. The difference of diagnostic methods and tests improves the detection of dyschromatopsia. The requirement is the correct choice of tests, correct mode and correct interpretation of results gained for each individual dyschromatopsia, i.e. profession.

\section{KEY WORDS}

$\sim$ Colour vision

$\sim$ Seafarers

$\sim$ Standards

$\sim$ Protocols

University of Split, University Hospital Centre Split, Department of Ophthalmology, Split, Croatia

e-mail: veljko.rogosic@st.t-com.hr

a. University of Split, University Hospital Centre Split, Department of Ear-NoseThroat, Split, Croatia

b. University of Split, University Hospital Centre Split, Department of Internal Medicine, Split, Croatia

c. University of Split, Faculty of Maritime Studies, Split, Croatia

\section{INTRODUCTION}

The perception of colour allows the individual to use chromatic impressions in emotional, artistic and professional areas. The present conditions of life involve all our senses, especially visual, in which colour vision is central.

Recently, research of colour vision has aroused interest with many authors to undertake more intensive investigation of dyschromatopsia (colour vision disorder) (Čupak, 1994; Staničić, 1991). The prevalence of congenital dyschromatopsia differs among nations, races, and ethnic groups and genders. The reasons for this are seen in the geographical, climatic diversity, and because of migration and mixing of different nations and races throughout history, especially now in the 21 st century, but also biological inheritance factors (Flecher and Voke, 1985).

Some authors around the world due to different diagnostic methods and tests got different results. Therefore, it is necessary to note that partly due to the above mentioned reason differences were found in the presence of congenital dyschromatopsia even among members of the same nations, races, cultures and ethnic groups (Cvetnić, 1999; Cvetnić, 1990, Rogošić et al., 2003) (Table 1).

With different nations and races outside Europe the occurrence of dyschromatopsia varies from e.g. Jews up to 4.0 \%, African Americans 3.7 \%, to Eskimoes 1.0 \% (Peić, 1976; Peić, 1977).

Congenital colour vision disorders are more common in men.

Normal colour vision is called normal trichromacy, and colour vision disorders dyschromatopsia or daltonism, and they are divided into: 
- dichromacy - partial colour blindness (anopia - blindness for a particular colour; protanopia - blindness for red colour, deuteranopia - blindness for green colour and tritanopia blindness for blue colour),

- anomalous trichromasia - colour amblyopia (reduced perception of one of the basic spectrum colours; protanomalia - reduced sense of red colour, and deuteranomalia - reduced sense of green colour and tritanomalia - reduced sense of blue colour),

- transition forms (extreme anomalies) and anomalies for pigment colours (incorrect on pseudoisochromatic tables, whereas on anomaloscope they have a normal anomaly quotient (AQ) ranging from 0.65 to 1.3 ) and

- monochromia or achromatopsia (blindness for all colours).

As dichromats are aware of their deficiency since their youth, they do not show interest for professions for which normal colour vision is necessary (rail, air, maritime or road traffic, as well

Table 1. The frequency of dyschromatopsia according to countries in Europe.

Source: Defective colour vision. R. Fletcher, J. Voke.

\begin{tabular}{cc}
\hline State & Dyschromatopsia (\%) \\
\hline Greece & 7.9 \\
\hline Belgium & 7.1 \\
\hline Great Britain & 7.2 \\
\hline Norway & 8.0 \\
\hline Croatia & 8.5 \\
\hline
\end{tabular}

as certain branches of industry).

Anomalous trichromats (colour amblyopia) are detected by accident, during medical check-ups, in professional orientation, selection and examination in occupational medicine practitioner's dispensary for professions which require normal colour vision. They represent a group that has to be diagnostically processed in detail.

Normal colour vision is necessary in different professions, and Verriest describes the division into three categories of professions which depend on colour vision (Verriest and Uvijls, 1977; Sloan, 1961):

1. Professions requiring completely normal colour vision: professional traffic.

2. Professions requiring normal colour vision, but in which instruments or suggestions of colleagues assist in colour vision problems.

3. Professions in which normal colour vision is desirable, but is not required.
Daily investigations of colour vision are not in the best way defined by mode or recognisability of colour vision disorder. Therefore, in occupational medicine dispensaries it is necessary to set up cooperation with an ophthalmologist, who will determine the type and degree of dyschromatopsia using appropriate diagnostics. Thus, $8.0 \%$ of dyschromatic population is given possibility to be timely advised as for the selection of an appropriate profession. An erroneous interpretation of the data gained based on a single simple test, e.g. pseudoisochromatic tables can have adverse consequences during professional orientation. ${ }^{(1)}$ Since normal colour vision is necessary for many professions, common criteria are also necessary especially in the assessment of extreme cases and pigment anomalies, with the application of diagnostic methods and tests providing the most accurate results for each colour vision anomaly (Sloan, 1961).

At present, for diagnostics of colour vision disorders there are various diagnostic methods and tests at disposal. Differences among diagnostic methods and tests improve detection of colour vision disorders, by correct selection of tests, mode and correct interpretation of data gained for each individual disorder. With such an attitude and activity we achieve new answers to existing disagreements and controversies within the profession. It is nowadays generally accepted that qualitative and quantitative research of colour vision can be carried out with the same accuracy and same iterativeness, such as e.g. the one in vision field testing. Clinical practice lags behind in the realization of adoption of new diagnostics and a simpler standard-protocol, thus contributing to insufficient understanding of colour vision testing. The diagnostic contribution to research of colour vision disorder is relatively weakly represented in literature, and its importance is insufficiently realized. For this reason there is a small number of ophthalmologists who daily deal with this area of work (Sloan, 1961).

The official standards for colour vision testing in traffic have not followed the development of traffic, especially in the case of maritime traffic. At the 43rd Meeting of Sub-Committee on Standards of Training and Watch-keeping, 30 April - 4 May 2012 in London, England IMO (International Maritime Organization) posed the problem of out datedness of methods and tests for testing colour vision in seafarers. The existing methods and tests that are mandatory for testing colour vision of seafarers are out-of-date and expensive. Since the Sub-Committee has not managed to propose new methods and tests for colour vision testing, they reached the decision to postpone the discussion for the 44th meeting of STW Sub-Committee, and to collect new proposals by IMO member-countries (London, England 13-17 May 2013).

1 This specially refers to to extreme anomalies (border groups of colour vision disorders) and pigment anomalies (persons who cannot read pseudoisochromatic tables), and for whom effective diagnostics means being able or unable for the profession wanted. 


\section{DIAGNOSTIC METHODS FOR COLOUR VISION DEFICIENCY}

Four basic methods for diagnosing colour vision disorders, their types, sub-types and degrees of defect, i.e. for determination of anomaly quotient (AQ) are widely known:

- Method of denomination or naming colours;

- Method of comparison of colours;

- Method of discrimination or separation of colours;

- Method of equalisation of colours.

\subsection{The method of denomination or naming the colours provided}

The method of denomination or naming is used with the aid of special lamps with filters of certain colours, while the testee names the colour provided. It is possible to create conditions existing in real life in traffic, such as conditions of reduced visibility. Special lamps, the so called lanterns (Martin lantern), that are used for colour vision testing in the army, police, navy, rail, air, road traffic, and that serve for colour vision testing in hard working conditions (Martin et al., 1976). Their great disadvantage is that they cannot actually diagnose colour disorder, or its degree, but they triage candidates who do well with coloured signal devices. Except in photopic conditions (well-lit conditions), it is possible to carry out research in scotopic conditions (in the darkness) (Martin et al., 1976).

Numerous authors such as Pierce, Sloan and Altman, Wright, Bidovec, Pickford and Lakowski emphasize the need for other appropriate methods and tests that would allow correct selection of professionals of different profiles with satisfactory colour vision for certain branches of industry, especially traffic, as well as army and police (Sloan and Habel, 1955; Wright, 1946; Pickford and Lakowski, 1960).

\subsection{The method of comparison of the colours provided}

The method of comparison of the colours provided uses Holmgren's balls of wool or pieces of different colour paper according to Seebeck that are mostly out of use nowadays. The doctor sorts out a sample ball of a certain (basic) colour, and the testee from the remaining pile of the balls of wool sorts out the remaining balls of the same or similar colour.

Research can also be carried out using differently coloured circular discs or pawns that are of different colour saturation, and the aim is for the testee to put all pawns in such an order that each following pawn is by colour the most similar to the preceding pawn. Here belong the small Farnsworth panel D-15 test and large 100 Hue-Farnsworth-Munsell test. On that basis modifications to 40 Hue Lanthony test and Farbtest 28 Hue red test were made. In special diagrams or schemes the order in which the testee put the pawns is recorded and on the basis of this record the conclusion is reached as for the existence of colour vision disorder and its type, red, green or blue (colour disorder axis) (Sloan and Habel, 1955; Wright, 1946; Pickford and Lakowski, 1960).

The performance of Farnsworth panel D-15 test has to be carried out in daylight. Pawns must not be touched with fingers, or exposed to the light for an extended period of time, so they are kept in a box. The period of test performance is not preset, but it is recorded and becomes an element of assessment of ease with which testing is performed. The order of testing starts from the reference fixed pawn, and the testee gradually classifies the remaining pawns according to the similarity in colour of each pawn with the previously classified one.

\subsection{The method of discrimination or separation of the colours provided}

The method of discrimination or separation uses pseudoisochromatic plates (PIC) (Figure 1). The most widely used are pseudoisochromatic plates of Ishihara and Stilling, but also the plates of other authors such as: Polak, Rapkin, Bostrem, BostremKugelberg, Valhagen, Hardy-Rand-Rittler (HRRAO), Toko Medical College (TMC), etc. On these plates, i.e. boards there are dots (numbers, letters and figures) of different sizes and colours that are put in such an order that a person with colour vision disorder does not recognize them. These plates are extremely suitable for triage and fast screening of a larger number of testees. They fall into the group of pigment tests.

The term pseudoisochromatic plates originates from the fact that these dots are different in colour, but equal in saturation (quality of a colour related to its purity, when a colour is not mixed with other colours), so that a person with colour vision disorder sees different colours as one and the same colour (pseudoisochromia), i.e. he/she gets a false impression that it is the question of one and the same colour and thus cannot distinguish the number, letter or figure provided from the background and name them (Sloan and Habel, 1955; Wright, 1946; Pickford and Lakowski, 1960).

\subsection{The method of equalisation of the colours provided}

The method of equalisation of colours with Nagel anomaloscope of the old type I or newer type I/ is the spectrum test, i.e. the test with coloured lights.

Beside Nagel anomaloscope type /l that is mostly in use nowadays and is considered the most reliable device for testing colour vision, especially in the case of congenital dyschromatopsia of the red-green axis, newer generation anomaloscopes are also used such as Oculus Heidelberger anomaloscope (HMC), Tomey all color anomaloscope that can also diagnose the blue-yellow colour vision disorder. Similar older devices (colorimetres) that 

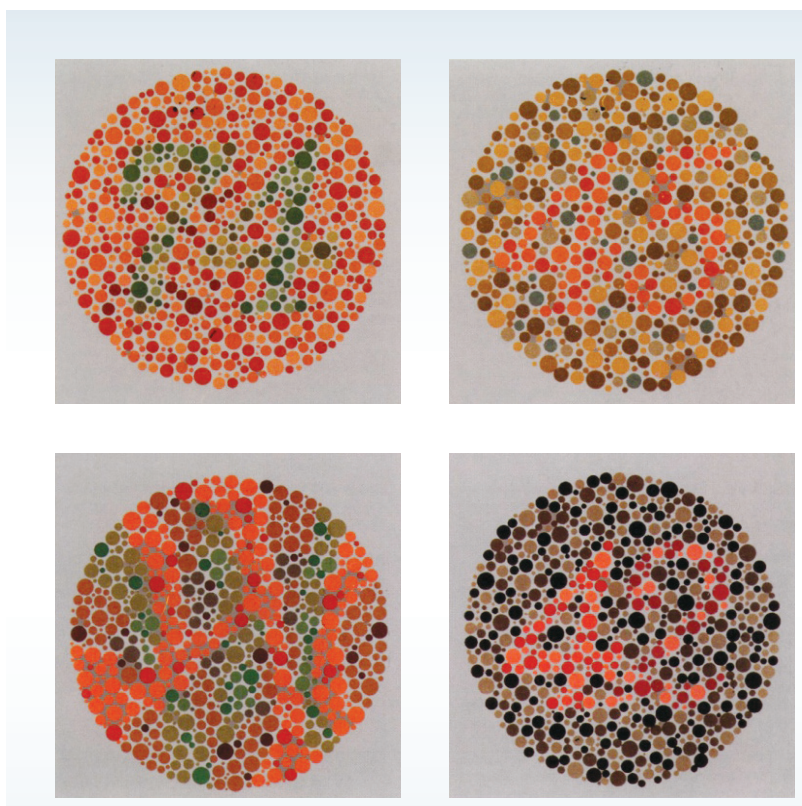

Figure 1. Example from pseudoisochromatic Ishihara tables. Source: K. Čupak. Oftalmologija.

are not in use any more due to weaker verification of certain colour vision disorders are: Gilles-Archer test, Edrigme-Grenova and Beyne lantern (Sloan and Habel, 1955; Wright, 1946; Pickford and Lakowski, 1960), Figure 2.

\section{DIAGNOSTIC TESTS FOR COLOUR VISION DEFICIENCY}

Tests for detection and classification of dyschromatopsia, i.e. colour disorder are numerous and classified into two major groups:

- tests with pigment colours, the so called pigment tests (pseudoisochromatic tables and tests with coloured pawns, or the so called panel tests);

- tests with coloured lights, the so called spectrum tests (anomaloscopes and partially lanterns) (Sloan and Habel, 1955; Wright, 1946; Pickford and Lakowski, 1960).

According to their differential-diagnostic abilities spectrum tests are divided into three basic groups, and they are:

- dychotomic diagnostic tests;

- qualitative diagnostic tests;

- quantitative diagnostic tests.

\subsection{Dichotomic diagnostic tests}

Testing which can effectively and with the use of fast
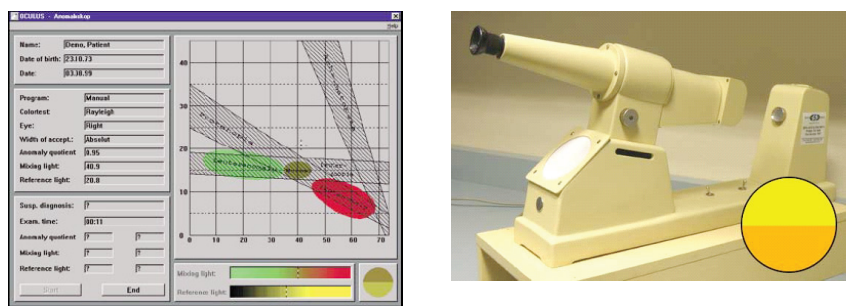

Figure 2. Comparison of recent Oculus anomaloscope of Heidelberg multi-colour type (HMC) and anomaloscope Nagel type II. Source: http://www.colblindor. com/2010/02/23/color-blindness-tests/

screening method isolate, i.e. triage normal trichromats (persons with normal colour vision) from dyschromatoptics (daltonists) is carried out by dichotomic tests for testing sense of colour, i.e. colour vision, and these are:

- Holmgren Wool test;

- Pseudoisochromatic tables according to Stilling;

- New London Navy Lantern test (NTL).

Holmgren Wool test includes 125 differently coloured balls of wool and 3 balls of coloured standards. The testee should assess similarity of different balls according to preset standards, sorting them out into three groups according to the nuance of the basic colour.

Pseudoisochromatic plates of Stilling have as background differently coloured dots of the doubled number type. Persons with colour vision disorder read one, and persons with normal colour vision the other. In research lighting and the angle at which one looks at the tables play important parts. If the testee does not distinguish more than 4 plates, he/she is classified into the group with colour vision disorder for red-green spectrum. Modifications of these plates also have the ability of detecting blue-yellow disorder.

On a similar principle pseudoisochromatic plates of Ishihara, Rapkin, Boston-Kugelberg, Dvorin, The American Optical Company Pseudoisochromatic test, HRRAO test, as well as plates of Volhagen, TMC, Matsubara plates and many others have been devised.

New London Navy Lantern test (NTL) has been improved by Farnsworth. It is used in the navy for military and civil purposes in testing extremely red-green disorder of colour vision. The testee is shown pairs of coloured lights that he/she has to name in hard working conditions, i.e. conditions of reduced visibility (simulation of twilight, dark, rain, fog and alike).

\subsection{Qualitative diagnostic tests}

Some pseudoisochromatic plates beside dichotomic plates 
also have plates for qualitative testing, i.e. diagnosing red-green colour disorders, and some plates can test blue-green colour vision disorders as well. Into this group fall:

- Ishihara pseudoisochromatic tables;

- $\quad$ Rodenstock orthorater R 7 with test plate No. R 173

Of all tests the Ishihara tables are nowadays the most widely used. They contain the starting plate that is followed by four series of plates of larger or smaller number of tables with which systematization has to be perfectly known (Pickford, 1946) (Table 2).

Some editions of these PIC plates are found in a reduced form of 24 or increased to 38 plates, while the main characteristics of plates in the series have been retained. There are also plates adjusted for children and analphabets by the same or different authors.

Nowadays fast screening and triage of candidates is often carried out using Rodenstock orthorater $R 7$ with the test plate No. $R 173$ especially in occupational medicine dispensaries (e.g. seafarers' medical check-up). Orthorater allows differentiating colour vision disorders quickly and reliably, while its disadvantage is that it cannot be used to test tritanomaly or tritanopia. The same orthorater can also be used, beside testing colour vision to which in this case daily or artificial light, or visual acuity have no effect, to test binocular vision, as well as stereo vision etc. During testing the testee can use one or both of his/her eyes. The test plate has contrary, the so called bipartite fields of identical combination of glass filters for colours, and in the testee's conscience they create a fusionally unique picture. The plate has 6 combination possibilities that while turning are shown to the testees. In 5 positions the fields are of different colours, while in one position the fields are of the same colour (it serves to detect stimulants). The testee does not have to name the colour, but only give an answer such as "similar" or "different.

\subsection{Quantitative diagnostic tests}

Of all colour vision tests after Ishihara plates the most significant are quantitative diagnostic tests such as:

- Nagel II anomaloscope ;

- 100 Hue-Farnsworth-Munsell test, i.e. its reduced modifications (Martin et al., 1976; Sloan and Habel,1955; Wright, 1946; Pickford and Lakowski, 1960; Pickford, 1949).

There are 2 types of Nagel anomaloscope:

- type / for testing red and green colour sense (out of use) and; - type /l with wider possibilities of more accurate diagnosing.

Table 2. Division of colour vision disorders according to pseudoisochromatic Ishihara tables.

$\begin{array}{lll}\text { Series } \quad \text { Plate } & \text { Readability }\end{array}$

0. 1 All: normal trichromats and dichromats.

1. 2 to 9 Normal trichromats and dichromats (protans and deutans respond in the same manner). G. Verriest warns of plates 4 and 5 where even normal trichromats can make mistakes.

2. 10 to 17 Read only by persons with normal colour vision, because coloured confetti-dots together with the background are made in such a way as to cause confusion with red and green dichromats.

3. 18 to 21

This series contains plates in which persons with colour vision disorder distinguish numbers, while normal trichromats cannot see them.

This series allows more accurate distinguishing of different dyschromatopsias, i.e. whether colour vision defect is in red or green colour. Each plate contains two digits of different

4. 22 to 25 colour (red and purple) on grey background. A protan (red colour daltonist) confuses the redness of the first digit with the greyness of the background. He reads the second digit only. A deutan (green colour daltonist) acts inversely and reads the first digit only as he cannot distinguish the purple colour of the second digit confetti. 
Anomaloscopes belong to the group of quantitative diagnostic tests. They are expensive diagnostic devices handled by specialists-ophthalmologists. They represent a basic diagnostic means for reaching a final expertise, i.e. opinion on colour vision deficiency, especially those related to professional traffic, and in accordance with the valid codes. It is used in all major medical centres.

Another type of tests, the so-called panels are easier for the patients, especially smaller variants (modifications) such as 40 Hue Lanthony and Panel D-15 test. These tests can fairly successfully be done by medium and higher medical staff, wherein the specialist-ophthalmologist assesses the graphic results, just like in vision field reading. It is highly suitable for everyday work in ophthalmological dispensaries.

100 Hue-Farnsworth-Munsell test has 85 coloured pawns. Some of its modifications, among which the best known is 40 Hue Lanthony test panel, is the most accurate in determining chromatic ability in detecting dyschromatopsia. In order to avoid the difficulty of doing the test and the required longer time for the testees taking 100 Hue-Farnsworth-Munsell, it is possible to replace it by an easier modification such as 40 Hue Lanthony test or Panel D-15 test (Sloan and Habel,1955; Wright, 1946; Pickford and Lakowski, 1960; Pickford, 1949).

D15 test panel includes testing using differently coloured circular discs or pawns of different saturation and the aim of the testee is to put the coloured discs in such an order as to follow by each disc the previous one that is most similar to it in colour.

\section{PROPOSAL OF NEW STANDARD FOR TESTING COLOUR VISION OF SEAFARERS}

The colour accessories, i.e. tools for colour testing, with the selection of diagnostic methods and tests, have to cover all types of dyschromatopsia (colour vision deficiency), and they also have to precisely determine each type of colour vision defect, i.e. they have to provide a qualitative and quantitative response (AQ).

According to our experience and opinion professional seafarers should be subjected to a medical check-up in ophthalmological dispensaries, that are equipped with all kinds of tests for complete diagnosing or testing of colour vision deficiencies or when such a defect is suspected. The most appropriate combinations of accessories or the standard for colour vision testing of congenital and acquired dyschromatopsias with their advantages and disadvantages are represented by SWOT analysis (Strengths, Weaknesses, Opportunities, Threats) in Table 3.

With colour vision testing investigation has to be carried out in a preset period of time and working conditions, and in accordance with the instructions laid down for doing each individual clinical test separately. With the acquired colour vision disorders as a difference from the congenital ones colour retesting is very often carried out (the same instrument and the same tester). The importance of being familiar with the advantages and disadvantages of each particular test, as well as an appropriate selection of a particular test is crucial for the correct diagnosis of colour vision disorder. Professionals working in the field of traffic in special working conditions can additionally be tested using New London Navy Lantern test (NTL), in which the testee is shown pairs of coloured lights that he/she should name in hard working conditions, i.e. conditions of restricted visibility (simulation of twilight, dark, rain, fog etc.). So, the method of denomination or naming is used with the aid of special lamps with filters (lanterns) of certain colours, and the testee determines, names the colour provided. NTL is mostly used in the navy for testing extreme redgreen colour vision defects (Tredici et al., 1999; Cole et al., 2007; Cole, 2007).

From the above mentioned clinical experiences, studies and papers there should appear new, modified, common and simplified, but at the same time reliable laws, or codes applicable to all countries, and related to colour vision testing in professional traffic, especially in the merchant navy, actually under the leadership of: IMO and Commission Internationale de I'Eclairage (CEI) (International Maritime Organization, 2012).

\section{DISCUSSION AND CONCLUSION}

The technical and technological development of traffic and traffic lanes has enabled economic progress. In maritime affairs there has been a significant increase in ships' speeds and their sizes that represents an additional hardship for already burdened seafarers. Although the development of electronic navigation devices has enabled watch-keeping and navigation in conditions of restricted visibility (night, fog, etc,), observation of the area surrounding the ship and visual assessment of the situation has so far remained an important factor of safe navigation. Optical omission often leads to unwanted situations. Therefore, it is of particular importance to test seafarers' vision both for colours, and vision acuity, and possibly to diagnose diseases due to the influence of UV radiation e.g. of the Sun (cataract, etc.). For professional seafarers the testing of colour vision is significant. This problem has also been recognised by IMO at the 43rd Meeting of STW Sub-Committee. IMO has not reached any conclusion on the methods and standards of colour vision testing, but has invited the member countries to propose new standards because the existing ones are considered outdated and economically demanding.

In Croatia, according to the relevant Code for the determination of health conditions of crew-members on board sea vessels and inland vessels (NN 111/02), (Official Gazette of the Republic of (roatia), an anticipated medical check-up, among other things, obligatorily includes visual ability testing (function of long-distance visual acuity using optotype, short-distance visual acuity using Jäger optotype, as well as long distance and short 
Table 3. SWOT analysis of the methodology of testing colour vision of seafarers.

\begin{tabular}{|c|c|c|c|c|}
\hline & Strenghts & Weaknesses & Opportunities & Threats \\
\hline $\begin{array}{l}\text { Rodenstock } \\
\text { orthorater R } 7 \text { test } \\
\text { with board No. R } \\
173\end{array}$ & $\begin{array}{l}\text { Screening, triage of } \\
\text { a large number of } \\
\text { testees and detection } \\
\text { of simulants. }\end{array}$ & $\begin{array}{l}\text { It cannot test blue } \\
\text { deficiency. }\end{array}$ & $\begin{array}{l}\text { A fast and reliable } \\
\text { test. }\end{array}$ & $\begin{array}{l}\text { Careful about } \\
\text { simulants. }\end{array}$ \\
\hline $\begin{array}{l}\text { Pseudoisochromatic } \\
\text { Ishihara and } \\
\text { Stilling plates for } \\
\text { adults, children and } \\
\text { analphabets }\end{array}$ & $\begin{array}{l}\text { Isolates reliably and } \\
\text { quickly persons } \\
\text { with normal colour } \\
\text { vision from persons } \\
\text { suspected of having } \\
\text { colour vision disorder. }\end{array}$ & $\begin{array}{l}\text { The testes can learn } \\
\text { the order of the } \\
\text { plates by heart. Not } \\
\text { suitable for testing } \\
\text { blue deficiency. }\end{array}$ & $\begin{array}{l}\text { Modification of } \\
\text { Stilling plates can } \\
\text { also provide response } \\
\text { for blue-yellow } \\
\text { deficiency. It provides } \\
\text { response on persons } \\
\text { with pigment colour } \\
\text { anomalies. }\end{array}$ & $\begin{array}{l}\text { Stilling plates - } 19 \text {. } \\
\text { They have a very bad } \\
\text { print. The edition has } \\
\text { been withdrawn. }\end{array}$ \\
\hline
\end{tabular}

\begin{tabular}{|c|c|c|c|c|}
\hline $\begin{array}{l}\text { Nagel II or Oculus } \\
\text { Heidelberg } \\
\text { multicolor } \\
\text { anomaloscope } \\
\text { (HMC) }\end{array}$ & $\begin{array}{l}\text { Nagel II is the most } \\
\text { reliable instrument } \\
\text { for testing colour } \\
\text { vision disorders } \\
\text { especially congenital } \\
\text { anomalies, providing } \\
\mathrm{AQ} \text {, i.e. response on } \\
\text { the degree of red- } \\
\text { green colour vision } \\
\text { deficiency. }\end{array}$ & $\begin{array}{l}\text { Persons with pigment } \\
\text { anomalies do the test } \\
\text { with NAD AQ results. }\end{array}$ & $\begin{array}{l}\text { More recent HMC } \\
\text { instrument can also } \\
\text { provide colour vision } \\
\text { result for blue-yellow } \\
\text { deficiency. }\end{array}$ & $\begin{array}{l}\text { The shutter must } \\
\text { be closed to the } \\
\text { maximum, and the } \\
\text { eye of the testee } \\
\text { must be previously } \\
\text { adapted to light. }\end{array}$ \\
\hline $\begin{array}{l}40 \text { Hue Lanthony or } \\
\text { Panel D-15 test }\end{array}$ & $\begin{array}{l}\text { Simplified } \\
\text { modifications of } 100 \\
\text { Hue-Farnsworth- } \\
\text { Munsell test } \\
\text { provide an equally } \\
\text { appropriate and } \\
\text { fast response on the } \\
\text { existence and type of } \\
\text { colour vision disorder. }\end{array}$ & $\begin{array}{l}\text { Not absolutely } \\
\text { suitable for } \\
\text { congenital colour } \\
\text { vision disorders. }\end{array}$ & $\begin{array}{l}\text { They are an excellent } \\
\text { complement to the } \\
\text { results obtained } \\
\text { using anomaloscope. }\end{array}$ & $\begin{array}{l}\text { This test is therefore } \\
\text { the most suitable for } \\
\text { detecting acquired } \\
\text { dyschromatopsias in } \\
\text { the course of life, or } \\
\text { service. }\end{array}$ \\
\hline
\end{tabular}

distance vision using appropriate instruments for multifunctional testing of vision sense, colour sense using pseudoisochromatic plates and appropriate instruments for multifunctional testing of vision, binocular vision, phoria, fusion, depth perception and vision field by instruments for multifunctional testing of vision sense, and mesopic vision, or fast adjustment to darkness by appropriate instruments).

A previous medical check-up is done, in accordance with the so far valid regulations, before issuing seaman's or boater's book, before the first employment and before enrolling in educational institutions of all levels of education for seafaring and boating professions.
The crew-members of the deck department and candidates for entering nautical departments of educational institutions at all levels of education for seafaring and boating professions have to be able to properly distinguish colours. The crew-members of the deck department and candidates for entering nautical departments of educational institutions at all levels of education for seafaring and boating professions have to have regular stereoscopic vision and vision field as well as the adjustment to darkness within normal limits.

For crew-members in other vessel's departments there are no special requirements as far as visual abilities are considered, provided that with or without correction their 
abilities are sufficient for successful performance of their tasks, with the obligation of wearing glasses or contact lenses and being in possession of a spare pair of glasses or contact lenses if the correction is necessary (Pravilnik o utvrđivanju uvjeta zdravstvene sposobnosti članova posade pomorskih brodova i brodova unutarnje plovidbe, 2002).

The prerequisite of creating clinically suitable methods of testing colour vision especially in the rail traffic emerged following the rail accident at Lagerlund as far back as 1875 . Three years after this rail accident in 1878 Holmgren introduces his already traditional wool balls offering thus the first test for detecting congenital colour vision disorders, and afterwards a whole range of new methods and tests by different authors appeared (Huddart, 1968; Cumberland et al., 2005).

Beside congenital colour vision disorders, of increasing significance are also the acquired disorders, frequent in cases of professional diseases of eye lens, retina or visual pathway. All of this requires common criteria for assessment of individual cases and application of such diagnostic methods and tests providing the most accurate and complete results.

The category to be paid special attention in the diagnostics of colour vision disorders are the transition forms of dyschromatopsia, between persons with normal colour vision on the one hand and persons with colour vision disorders on the other, such as: extreme deuteranomaly, extreme protanomaly, and pigment colours anomaly. Detection of these disorders requires application of additional diagnostic procedures that are not routinely applied, especially not in occupational medicine dispensaries.

It should be mentioned that testing with the use of special lamps, the so-called lanterns, with different filters of certain colours serves only for the testee to name the colour provided in special simulated conditions in traffic, such as e.g. conditions of restricted visibility. It is their great disadvantage that they cannot actually diagnose colour vision disorder, but they triage candidates who do well or badly with coloured signal devices.

Consequently, we are of the opinion that the need should be emphasised for acceptance of other, suitable and simpler methods and tests that would allow the appropriate selection of professionals, especially those in the professional traffic.

The standard for testing colour vision disorders, i.e. vision is proposed:

1. Testing colour vision on Rodenstock orthorater R 7 with the test plate No. R 173 for a fast triage of the testees and isolating stimulants.

2. Testing with PIC tables of Ishihara consisting of 24 plates to detect persons with pigment colour anomalies.

3. Testing with Panel D-15 test to determine the type (axis) of colour vision disorder, if it exists.

4. Final, but also obligatory testing of colour vision on anomaloscope Nagel II for correct determination of AQ.
Accordingly, it is ouropinion that newlaws, or codes regulating testing of colour vision of professional traffic participants, especially seafarers should be adjusted and internationally coordinated.

\section{REFERENCES}

Cole, B.L., (2007), Assessment of inherited colour vision defects in clinical practice, Clinical and Experimental Optometry, 90(3), pp. 157-175.

Cole, B.L., Lian, K.Y., Lakkis, C., (2007), Using clinical tests of colour vision to predict the ability of colour vision deficient patients to name surface colours, Ophthalmic and Physiological Optics, 27(4), pp. 381-388.

Cvetnić, B., (1990), Nesklad nalaza u raspoznavanju boja na pseudoizokromatskim tablicama i anomaloskopu Nagel II, Doktorska disertacija, Zagreb: Medicinski fakultet.

Cvetnić, B., (1999), Raspoznavanje boja, Željeznica u teoriji i praksi, 25, pp. 67-69.

Cumberland, P., Rahi, J.S., Peckham, C.S., (2005), Impact of congenital colour vision defects on occupation, Archives of Disease in Childhood, 90(9), pp. 906-8.

Čupak, K., (1994), Oftalmologija: udžbenik oftalmologije, 2nd Edition, Zagreb: Nakladni zavod Globus.

Flecher, R. and Voke, J., (1985), Defective colour vision - fundamentals, diagnosis and management. 1st Ed. Bristol and Boston: Adam Hilger.

Huddart, J.G., (1968), An account of persons who could not distinguish colours, Philosophical Transactions of the Royal Society, 67, pp. 260-265.

International Maritime Organization. Colour vision. 43rd Meeting of Sub-Committee on Standards of Training and Watch-keeping, (2012) London, England, 30 April - 4 May 2012, 14, pp. 22-23.

Martin, L.C., Warburton , F.L., Morgan W.J., (1976), A standardised lantern for testing colour vision, British Journal of Ophthalmology, 23, pp. 1-20.

Peić, M., (1976), Doprinos testiranju prirođenih anomalnih trikromazija s posebnim osvrtom na veličinu anomalnog kvocijenta i fenomen obojenog simultanog kontrasta, Doktorska disertacija, Zagreb: Medicinski fakultet.

Peić, M., (1977), Nastavni tekst za postdiplomsku nastavu iz oftalmologije: Prirođene mane u raspoznavanju boja. 1st Edition, Zagreb: Medicinski fakultet.

Pickford, R.W., Lakowski, R., (1960), The Pickford-Nicolson anomaloscope British Journal of Physiological Optics, 17, pp. 131-50.

Pickford, R.W., (1949), A study of the Ishihara test for colour blindness, British Journal of Psychology, 40(2), pp. 71-80.

Pravilnik o utvrđivanju uvjeta zdravstvene sposobnosti članova posade pomorskih brodova i brodova unutarnje plovidbe. Zagreb: Narodne novine d.d., 111/02, str. 1802.

Rogošić, V., Bojić, L., Karaman, K., (2003), Congenital dyschromatopsias in Split, Croatia, Arhiv za higijenu rada i toksikologiju, 54, pp. 1-4.

Sloan, L.L., Habel A., (1955), Colour signal systems for the red-green colour blind, Journal of opt soc, 45, pp. 592-598.

Sloan, L.L., (1961), Evaluation of the T. M. C. colour vision test, American Journal of Ophthalmology, 52, pp. 650-659.

Staničić, V., (1991), Oštećenja vida: biopsihosocijalni aspekti, 1st Edition, Zagreb: Školska knjiga.

Tredici, T.J., Mims, J.L., Culver, J.F., (1999), History, rationale and verification of colour vision standards and tests in the U.S. Air Force, Advisory Group for Aerospace Research and Development (AGARD) International Conference, Neuilly-sur-Seine, France,

Verriest, G., Uvijls, A., (1977), A spectral increment thresholds on a white background in different age groups of normal subjects and in acquired ocular diseases, Documenta Ophthalmologica, 43, pp. 217-248.

Wright, W.D., (1946), A trichromatic colorimeter with spectral primaries, Transaction of the Optical Society, 29, 225-241. 